\title{
Experimental Study on Seepage Characteristics of Fractured Rock Mass under Different Stress Conditions
}

\author{
Ma Haifeng $\mathbb{D},{ }^{1,2}$ Yao Fanfan $\mathbb{D}^{2},{ }^{2}$ Niu Xin'gang, ${ }^{2,3}$ Guo Jia $\mathbb{D}^{4},{ }^{4}$ Li Yingming, ${ }^{2}$ \\ Yin Zhiqiang $\left({ }^{1},{ }^{2}\right.$ and Li Chuanming ${ }^{2}$ \\ ${ }^{1}$ State Key Laboratory of Mining Response and Disaster Prevention and Control in Deep Coal Mines (Anhui University of Science \\ and Technology), Huainan, Anhui 232001, China \\ ${ }^{2}$ School of Mining Engineering, Anhui University of Science and Technology, Huainan, Anhui 232001, China \\ ${ }^{3}$ China Coal Technology and Engineering Group Chongqing Research Institute, Chongqing 400037, China \\ ${ }^{4}$ Anhui Academy of Coal Science, Hefei, Anhui 230001, China
}

Correspondence should be addressed to Yao Fanfan; 3299531763@qq.com and Guo Jia; kkkguojia@163.com

Received 8 September 2021; Accepted 23 October 2021; Published 20 November 2021

Academic Editor: Zhijie Wen

Copyright (c) $2021 \mathrm{Ma}$ Haifeng et al. This is an open access article distributed under the Creative Commons Attribution License, which permits unrestricted use, distribution, and reproduction in any medium, provided the original work is properly cited.

In order to obtain the mechanical behavior and permeability characteristics of coal under the coupling action of stress and seepage, permeability tests under different confining pressures in the process of deformation and destruction of briquette coal were carried out using the electrohydraulic servo system of rock mechanics. The stress-strain and permeability evolution curves of briquette coal during the whole deformation process were obtained. The mechanical behavior and permeability coefficient evolution response characteristics of briquette coal under stress-seepage coupling are well reflected. Research shows that stressaxial strain curve and the stress-circumferential strain curve have the same change trend, the hoop strain and axial strain effect on the permeability variation law of basic consistent, and the permeability coefficient with the increase of confining pressure and decreases, and the higher the confining pressure, the lower the permeability coefficient, the confining pressure increases rate under the same conditions, and the permeability coefficient corresponding to high confining pressure is far less than that corresponding to low confining pressure. The confining pressure influences the permeability of the briquette by affecting its dilatancy behavior. With the increase of the confining pressure, the permeability of the sample decreases, and the permeability coefficient decreases with the increase of the confining pressure at the initial stage, showing a logarithmic function. After failure, briquette samples show a power function change rule, and the greater the confining pressure is, the more obvious the permeability coefficient decreases.

\section{Introduction}

In mining engineering, high stress and the coupling effect of karst water pressure and the influence of multiple mining could lead to the structure change of the surrounding rock body, which not only could reduce the mechanical properties of rock itself but also easy to make the surround rock mass permeability changed significantly; rock permeability changed lead to mine water inrush, and mine roadway surrounding rock of roadway was one of the main causes of instability.

The actual underground engineering rock mass exists in a certain stress environment and is subjected to the dual action of external stress and internal stress. The stress state is a major factor affecting the permeability of rock mass [1]. For this reason, many scholars have conducted indepth research on the evolution law of permeability of underground engineering rock mass with the change of stress. Xu and Yang [2] measured the permeability of sandstone under short-term and long-term compression conditions and analyzed the influence of confining pressure on sandstone strength and failure mode. Hu et al. [3] conducted experimental studies on the mechanical behavior and permeability of saturated sandstone and obtained the evolution law of Biot coefficient and permeability with microcrack propagation. Wang et al. [4] conducted permeability tests 
on sandstone under different fluid pressures and concluded that the evolution of permeability of rock mass was closely related to the development of microcracks. Jiang et al. [5] conducted a permeability experimental study on brittle rock and concluded that the anisotropic damage of brittle rock is closely related to the change rate of permeability. Based on field investigations and previous tests on physical model, a numerical model of an anaclinal slope using the threedimension distinct element code software has been built to simulate the failure process of the physical model [6]. The permeability evolution of fractal-based two-dimensional discrete fracture networks during shearing under constant normal stiffness boundary conditions is numerically modeled and analyzed based on a fully coupled hydromechanical model. The effects of fractal dimension, boundary normal stiffness, and hydraulic pressure on the evolutions of mechanical behaviors, aperture distributions, and permeability are quantitatively investigated [7].

In order to understand the seepage mechanism of fractured rocks under stress, the tests on seepage characteristics of fractured rocks under varying confining pressures were carried out, and the law that the flow rate increased with the increase of the seepage pressure gradient and decreased with the increase of the confining pressure was obtained [8]. To study the damage development and permeability change in the process of rock excavation in roadways, the permeability evolution and damage for mudstone material under coupled stress-seepage was analyzed based on the stress-seepage damage coupling model [9]. The change rules of permeability, volumetric strain, and porosity under fluidsolid coupling during coal seam mining were studied based on the numerical model of a Darcy-Forchheimer flow in aquifers [10]. The tests of stress-seepage coupling of fracture of different particle size were carried out using the coupled shear-seepage test system of JAW-600 rock, and the permeability coefficient of quasisandstone increases exponentially with the increase of cranny hydraulic pressure [11]. The permeability of protected coal seam in the process of protective coal seam mining was studied; according to the changes of permeability, the protected coal seam was divided into initial permeability zone, permeability decreasing zone, and permeability increasing zones 1 and 2 [12]. Based on the Drucker-Prager criterion, the rock elastoplastic damage constitutive model was established aiming at the problem of surrounding rock excavation damage zone of tunneling in the rich water region, and the fully implicit return mapping algorithm was adopted to realize the numerical solution [13]. The relation between the anisotropic permeability matrix and effective stress was established, and the deterioration of strength parameters was considered by defining elastoplastic damage variables, and the characteristics of seepage and failure were analyzed by an improved multiphysics coupling model [14]. A stress-seepage-damage coupling model based on the finite element method was developed and first applied in HF in concrete dams, the crack propagation processes of Koyna dam, and a 1:40 scaled model dam using the coupling model [15].

The correction model of inertial resistance coefficient and permeability of the goaf was established by introducing the inertial resistance coefficient and shape factor of permeability, and the inertial resistance coefficient shape factor and permeability had good power function relationships with particle size [16]. Qiang et al. used the latest X-ray diffraction, scanning electron microscopy, and mechanical testing methods to analyze the physical, mechanical, and seepage characteristics of the key aquiclude and established the KAS damage state model for the stress-strain-permeability correlation of the composite rock mass and the non-Darcy seepage characteristics of the postpeak fractured rock mass. The research results have a certain guiding significance for the prevention and control of water inrush disasters and the rational development and utilization of coal resources based on KAS [17]. Dong et al. proposed a new coal quality characterization and prediction method for the prediction, early warning, and accurate identification of composite coal and rock dynamic disasters and concluded that the physical characteristics of coal in coal and rock dynamic disasters are between those of gas outburst and rock burst [18]. In order to study the gas outburst prevention theory of the coal seam permeability of the lower protective seam, $\mathrm{He}$ et al. put forward the basic hypothesis of the gas-solid coupling model of coal and put forward the permeability increasing coefficient of equivalent layer spacing by numerical simulation, which provides a theoretical basis for the gas drainage technology to prevent coal and gas outburst in the lower protective seam mining [19]. Zhou et al. analyzed the stress sensitivity of permeability and porosity of mudstone, coal, and sandstone based on Langmuir equation by overburden pressure permeability experiment of coal measures reservoir and concluded that the initial permeability and initial porosity of coal are significantly higher than those of mudstone and sandstone, and with the increase of effective stress, the permeability and stress sensitivity coefficients of coal, mudstone, and sandstone decrease in a wavy manner [20]. In order to study the effect of the difference swelling index on the evolution of coal permeability, Chuanzhong et al. established the coal permeability model and proposed the concept of differential swelling index, which theoretically defined the adsorption strain relationship of coal body, fracture, and matrix in equilibrium state, and clarified the effect of differential strain [21]. Zihao et al. studied the influence of effective stress and Klinkenberg effect on shale apparent permeability, used pulse decay permeameter to measure the core of shale formation in situ, and established a multiphysical shale transport model to consider the multiphysical coupling process in shale, to clarify the effect of bedding orientation on apparent permeability [22]. In order to study the unsteady seepage solution of hydraulic fracturing around vertical wells in oil and gas reservoirs, $\mathrm{Wu}$ et al. used numerical simulation method to establish the hydraulic fracturing influence model of vertical wells under the condition of unsteady seepage in oil and gas reservoirs and concluded that permeability and hydraulic gradient are the important factors determining whether hydraulic fracturing occurs in the rock [23]. In order to study the height of water flowing fractured zone in thin bedrock and thick clay coal seam, Hao et al. obtained the evolution law of coal reservoir in this area by means of field measurement, theoretical analysis, and numerical 
simulation, which provided an important theoretical basis for effectively preventing roof water hazards in mines [24]. In the study of permeability of clay-quartz mixture, Lu et al. used NMR and $40^{\circ} \mathrm{C}$ evaporation test to predict the permeability coefficient of quartz-clay mixture based on Timur-Coates model and obtained a simplified method to predict the permeability coefficient of quartz-clay mixture by NMR [25].

Zhou et al. established the model of the influence of creep deformation and matrix-fracture interaction on the permeability of deep coal and obtained that the permeability decreases with the decrease of pore pressure in the secondary stage and the initial stage of creep by using the fractional derivative transient pulse method and nonlinear least square method [26]. In order to study the permeability law of water-bearing coal seams under the condition of plastic flow, Guo et al. used the transient method to study the permeability changes of water-bearing coal seams and water-free coal seams and concluded that the internal fracture closure rate of water-bearing coals is lower than that of water-free coals, which is conducive to water storage and transportation [27]. Qinghe et al. studied the anisotropic permeability of different ranks of coal under the influence of $\mathrm{CO} 2$ adsorption and effective stress, conducted permeability tests under the conditions of cyclic loading and unloading and supercritical $\mathrm{CO}_{2}$, and concluded that the permeability of coal seams varies with coal ranks, and the permeability is anisotropic, showing that the permeability of parallel layers is greater than that of vertical layers [28]. Haifeng et al. used the method of pore mechanics test for Biot tensor of argillaceous rocks to obtain the gas permeability and elastic properties of clay rock pores and found that gas adsorption-swelling has a greater impact on the migration and mechanical properties of argillaceous rocks in the long-term gas migration process [29]. Ma et al. aimed at the problem of floor water inrush in deep mining of Dongjiahe Coal Mine, through numerical simulation and combining with acoustic emission information of RFPA software and field microseismic monitoring data, the permeability characteristics of fractured rock mass were obtained, which showed that the main direction of permeability changed greatly with the change of surrounding rock pressure when the surrounding rock pressure was different [30]. In the study of permeability damage of coal under cyclic loading, Long and Shimin adopted pulse attenuation method and combined with matrix shrinkage concept to summarize the evolution law of coal permeability and concluded that the evolution of permeability directly controlled the seepage behavior of underground fluid, and the damage of average permeability was affected by loading and unloading paths [31]. Liang et al. studied the creep characteristics and constitutive model of coal. A series of creep experiments were carried out under gas pressure and triaxial compression. It was concluded that the creep deformation characteristics of coal were related to gas pressure and deviatoric stress, and the nonlinear model obtained could accurately describe the whole creep stage of coal [32]. Based on the porosity elasticity theory and uniaxial strain condition, Mathias studied the gas storage coefficient and permeability function of coalbed methane mining, established three ana- lytical models to describe the changes of porosity and permeability, and concluded that without considering the gas adsorption strain, only one of the porosity models can obtain the correct uniaxial strain storage coefficient equation [33]. Yu et al. studied the permeability model of fractured rock mass and derived the formula of fracture permeability in theory and in combination with field experiments and concluded that the proposed permeability evolution description method and model can predict laboratory permeability data [34]. Xiaoyang et al. proposed a simple method of fitting pressure based on fracturing pressure drop under the condition of dynamic leakage coefficient, chose PKN model as the expansion model of hydraulic fracture, predicted the permeability of coal reservoir after fracturing by using the well test theory of water injection well, and concluded that the shape of hydraulic fracture is mainly determined by ground stress [35]. Shuaifeng et al. studied hydraulic fracturing sand-carrying permeability enhancement technology by high-frequency sand-carrying method and obtained that there are three stages in the evolution of cracks, and found that high-pressure fluid "water-sand" injection brings sand into high-frequency cracks, which produces propping force on the crack surface, hinders crack closure, and greatly improves gas permeability [36]. Luo studied the influence of water on the mechanical behavior of rock surrounding hard-rock tunnels [37, 38].

At present, the trend of coal mining into the deep is obvious; the deep coal seam and the surrounding rock of the roadway are in a complex environment, vulnerable to the coupling effect of high stress and high karst water pressure, and then easy to cause significant instability deformation characteristics. Therefore, an in-depth study of the mechanical behavior and permeability response characteristics and evolution law of coal and rock under stress-seepage coupling can provide a certain basic theory and basis for coal and gas outburst, water inrush accident prevention, and control of deep roadway surrounding rock stability control.

\section{Experimental Principle and Methods}

There are more than 10 kinds of methods for measuring rock permeability in the laboratory, which can be roughly classified into two categories: steady-state method and transient method. Because of steady-state method requires a large number of samples, a long test period, high cost, and confining pressure are not easy to control and other shortcomings. This experiment chooses the transient method to analyze the rock permeability and should pay special attention to when testing sample sealing and axial load is not zero, so the preset first strain value is not zero; confining pressure is greater than the pore pressure; pore pressure is higher than of the confining pressure; the plastic insulation tape and hot shrinkage in the sealed sample will be broken plastic cover test cannot be performed.

2.1. Experimental Principle. The principle of the water permeability test is shown in Figure 1 . In the figure, $\sigma 1$ is the axial pressure, $\sigma 3$ is the confining pressure, $p 1$ is the water pressure at the upper end of the specimen, and $p 2$ is the 


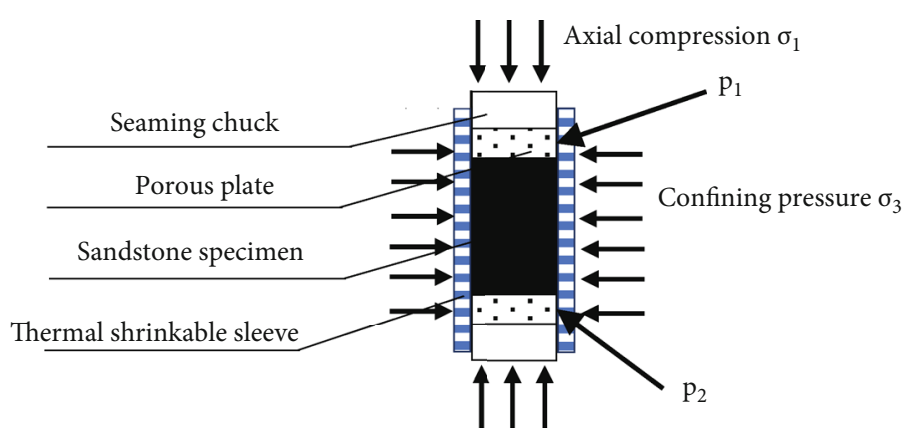

FIGURE 1: Sketch of permeability experiment principle.

water pressure at the lower end of the specimen. There is a permeable plate at both ends of the specimen, which is a steel plate with many evenly distributed holes The upper part of the permeable plate is the upper pressure head, and the lower part is the lower pressure head. There is a vertical hole in the center, and the plastic insulation belt and the heat-shrinkable plastic sleeve are used to seal the sample for the water flow channel.

In the test, the seepage flow was constant $(1 \mathrm{~mL} / \mathrm{min})$, and the permeability pressure difference between the two sections changed with the deviatoric stress loading. In the process of specimen deformation and failure, the non-Darcy flow will occur with the expansion and penetration of microcracks. The influence of flow velocity on the calculation of permeability coefficient should be taken into account. In the whole process of the test, the flow velocity through the cross-section of the sample is small $\left(8.5 \times 10^{-6} \mathrm{~m} / \mathrm{s}\right)$, so the Darcy steady flow method is adopted to test the permeability coefficient of the sample. That is, the permeability coefficient of the sample is calculated according to the measurement parameters such as the flow rate of the fluid through the sample and the permeability pressure difference between the two ends of the sample. The calculation formula is

$$
k=\frac{q L \gamma_{w}}{\Delta p A} \times 10^{-4},
$$

where $k$ is the permeability coefficient of the sample $(\mathrm{cm} / \mathrm{s}), q$ is the seepage flow through the sample $(\mathrm{mL} / \mathrm{s}), L$ is the length of the sample (mm), $\gamma_{w}$ is the bulk density of water $\left(\mathrm{kN} / \mathrm{m}^{3}\right), A$ is the cross-sectional area of the sample $\left(\mathrm{mm}^{2}\right)$, and $\Delta p$ is the permeability pressure difference between the two ends of the sample $(\mathrm{MPa})$.

2.2. Experimental Apparatus. Using MTS815 rock mechanics electrohydraulic servo system in the whole stress and strain in the process of a penetration test, the system has uniaxial compression, triaxial compression, and pore water pressure test, water seepage test, and other functions. The sample size is $50 \mathrm{~mm} \times 100 \mathrm{~mm}$, the maximum confining pressure is $60 \mathrm{MPa}$, the maximum axial deviatoric stress is $300 \mathrm{MPa}$, and the maximum pore water pressure is $60 \mathrm{MPa}$. The deviatoric stress loading can be carried out by controlling the pressure, displacement, and oil pump flow. Axial strain and circumferential strain can be measured simultaneously. The axial strain was measured by two linear displacement sensors (LVDT), and the circumferential strain was measured by a circumferential electronic strain gauge placed in the center of the sample height. The pore water pressure is applied from the bottom of the sample and is also the source of the osmotic pressure difference and seepage water. When the outlet valve connecting the upper end of the sample is opened, the pore water pressure at the upper end of the sample becomes 0 . Under the action of the pressure difference between the upper and lower ends, an approximate onedimensional seepage flow will be formed in the sample.

2.3. Specimen Preparation. The test samples are taken from 1232(1) working faces of the Panyidong Coal Mine in Huainan. The buried depth of the coal seam is about $720 \mathrm{~m}$, the average dip angle is $5^{\circ}$, and the average thickness is $2.3 \mathrm{~m}$. The coal removed from the working face is packed with plastic cloth and sent to the laboratory. The coal is crushed, and the particle size of coal with $60 \sim 80$ mesh is screened. The briquette is made into briquette samples with a briquette size of $\Phi 50 \mathrm{~mm} \times 100 \mathrm{~mm}$ after the briquette mold is prepared on the rigid testing machine of $2000 \mathrm{kN}$, and the forming stress is stabilized at $100 \mathrm{MPa}$ for 30 minutes. The briquette sample prepared is placed in the oven to dry and stored in the drying oven for test after cooling to room temperature. The prepared briquette samples are shown in Figure 2.

2.4. Experimental Scheme and Procedure. The samples used in the test are taken from no. 11 coal of Panyidong Coal Mine in Huainan. The uniaxial compressive strength of the samples is about $6.5 \mathrm{MPa}$, and the measured porosity is $12 \%-20 \%$. Before the penetration test, the samples were immersed in water for $48 \mathrm{~h}$ to reach the saturation state, to ensure that the seepage flow in the samples during the test was unidirectional.

The test procedure is as follows:

(1) The sample is sealed with a rubber sleeve to ensure that the oil in the triaxial pressure chamber in the test does not mix with the water in the sample

(2) Apply a preset confining pressure value to the sample 


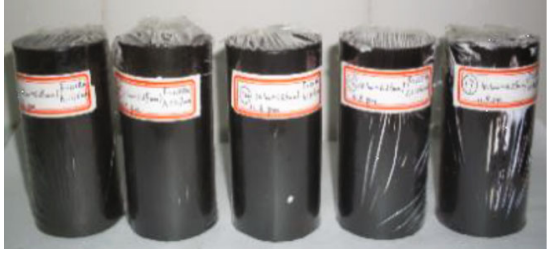

Figure 2: Part of briquette samples.

(3) Apply pore water pressure in a flow-controlled manner. A reasonable water flow rate can ensure that the maximum pore water pressure does not exceed the confining pressure when stable seepage is formed, and the pore water pressure value of the sample after destruction is not lower than the instrument range. The water flow rate used in this test is $1 \mathrm{~mL} / \mathrm{min}$

(4) Peak strength of the sample and pressure control $(1 \mathrm{MPa} / \mathrm{min})$ is applied to load; after that, the oil pump flow control $(0.05 \mathrm{~mL} / \mathrm{min})$ is applied to load until the specimen is damaged. The axial pressure is controlled by graded loading. The next load test was carried out after the pore water pressure stabilized at each load level

(5) The confining pressure values were applied in the test. Permeability tests in the process of deformation and failure were carried out on the samples under different confining pressure conditions using 2,4 , 6 , and $8 \mathrm{MPa}$. To reduce the error caused by the difference of samples, three samples were selected for testing under each confining pressure condition. The test scheme is shown in Table 1

\section{Results and Discussion}

3.1. Law of Penetration in the Full Stress-Strain Process. Permeability coefficient axial strain curves of samples under different constant confining pressures $(2,4,6$, and $8 \mathrm{MPa})$ were obtained, limited by length. Only the evolution curve of representative permeability deformation in the deformation and failure of each group of samples is listed here (as shown in Figure 3). Typical permeability test results for samples are presented in Table 2.

To obtain the coal deformation characteristics and permeability evolution response law under the stress-seepage coupling action, the volumetric strain and permeability response characteristics during the whole process of briquette deformation under different confining pressures were analyzed in this paper.

As can be seen from Figure 3 and Table 2, the stressstrain curve shape trend of briquette samples under different confining pressures is the same, and all of them have experienced five stages: nonlinear compaction stage, linear deformation stage, yield stage, strain-softening stage, and residual deformation stage. Under different confining pressures, the curves of permeability coefficient-axial strain are same, and the permeability coefficient of briquette samples
TABLE 1: Test scheme.

\begin{tabular}{lccc}
\hline \multirow{2}{*}{$\begin{array}{l}\text { Sample } \\
\text { number }\end{array}$} & $\begin{array}{c}\text { Sample size } \\
\text { Diameter/ } \\
\text { mm }\end{array}$ & $\begin{array}{c}\text { High/ } \\
\text { mm }\end{array}$ & $\begin{array}{c}\text { Confining pressure/ } \\
\text { MPa }\end{array}$ \\
\hline ST-2-1 & 49.6 & 99.6 & \\
ST-2-2 & 48.9 & 100.7 & 2 \\
ST-2-3 & 50.3 & 99.5 & \\
ST-4-1 & 48.9 & 99.8 & \\
ST-4-2 & 49.3 & 100.5 & \\
ST-4-3 & 50.2 & 99.6 & \\
ST-6-1 & 49.5 & 99.7 & 6 \\
ST-6-2 & 49.8 & 99.1 & \\
ST-6-3 & 49.3 & 99.3 & \\
ST-8-1 & 50.3 & 99.8 & \\
ST-8-2 & 49.6 & 100.4 & \\
ST-8-3 & 49.7 & 100.7 & \\
\hline
\end{tabular}

has experienced a slow decrease stage, an obvious increase stage, and a steady increase stage.

In the first stage of the stress-strain curve, with the increase of axial compression, the stiffness of briquette samples gradually increases, the curve curves upward, and the initial defects gradually close. This stage is the nonlinear compaction stage. At the same time, due to the decrease of porosity in the sample, the channel for fluid flow becomes narrower, resulting in the decrease of seepage velocity. In the second stage, the stress-strain curves of briquette samples all vary approximately linearly. Under the action of external load, the briquette coal samples are squeezed and staggered among the pulverized coal particles, the cohesion decreases, and the deformation cannot be recovered after unloading. In this stage, the original gap between the pulverized coal particles is filled, and the fluid permeability coefficient continues to decrease. From the third stage, the permeability coefficient of briquette samples changed from a decrease to a sharp increase. With the increase of stress, the shear movement between the briquette particles began to promote the stable crack expansion, the stress-strain curve bent downward, the stiffness decreased, and the briquette entered the yield deformation stage. Under the action of shear movement, pulverized coal particles squeeze and dislocate each other, resulting in a large number of cracks and resulting in a sharp increase in permeability coefficient. In the fourth stage, the briquette samples developed further based on the shear failure, and the bearing capacity began to decline and entered the strain-softening stage. The internal structure of the briquette determined that no stress drop would occur, and the seepage velocity of the briquette increased steadily. In the fifth stage, the axial stress of the briquette remains unchanged, but its axial strain gradually increases, and the coal sample begins to creep and enters the stage of residual deformation. At this point, although the axial stress is unchanged and the specimen is in axial compression, the transverse deformation is constantly expanding, so the seepage velocity is still increasing, but the growth trend is slow. 


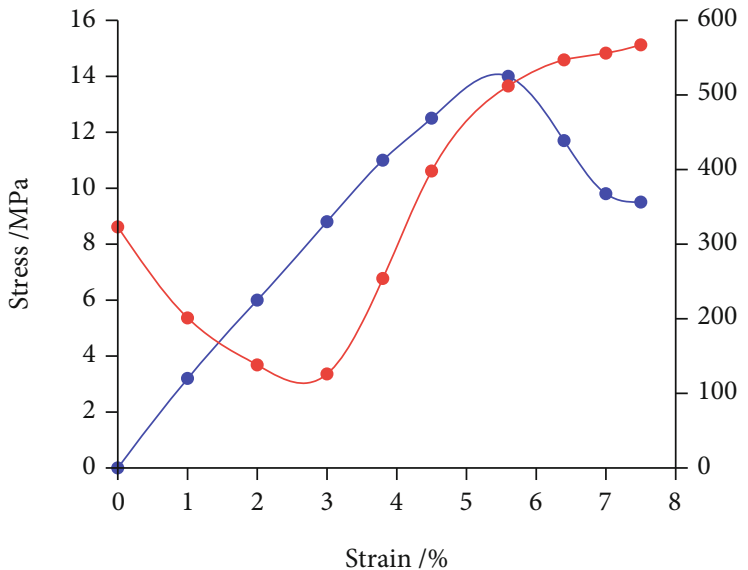

(a) Confining pressure $2 \mathrm{MPa}$

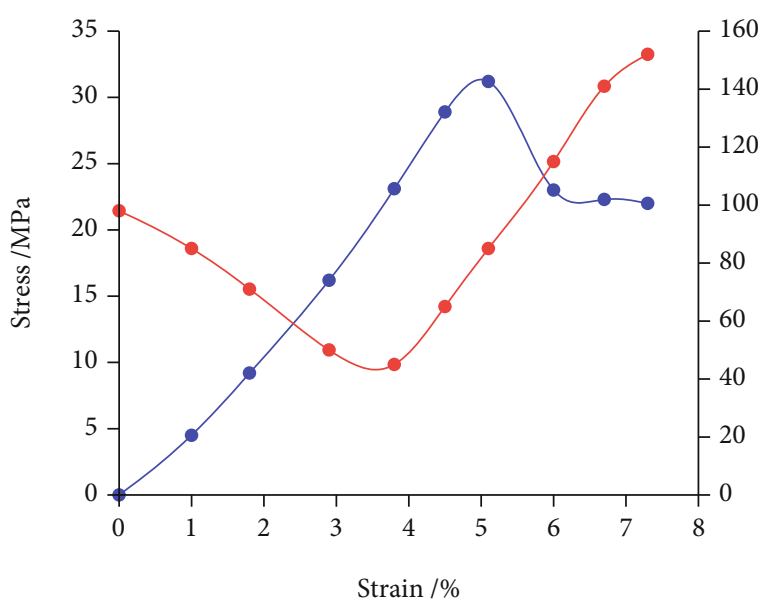

(c) Confining pressure $6 \mathrm{MPa}$

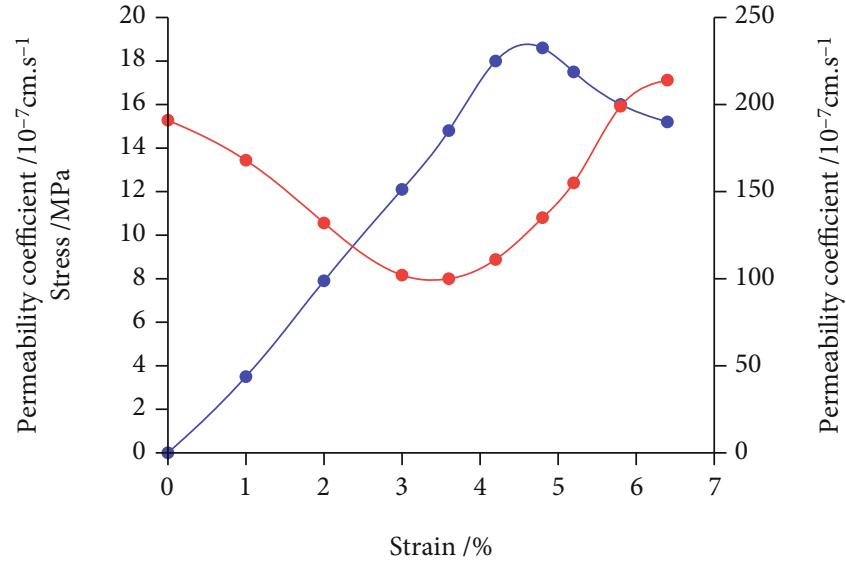

(b) Confining pressure $4 \mathrm{MPa}$

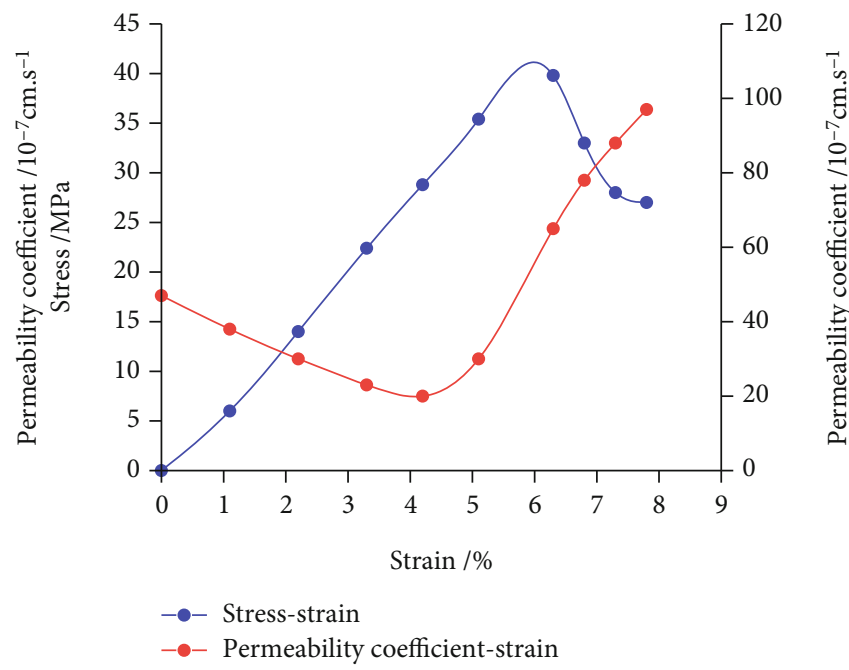

(d) Confining pressure $8 \mathrm{MPa}$

FIGURE 3: Variation curve of permeability coefficient during stress-strain process.

TABLE 2: Results of penetration test.

\begin{tabular}{lcccc}
\hline $\begin{array}{l}\text { Sample } \\
\text { number }\end{array}$ & $\begin{array}{c}\text { Confining } \\
\text { pressure/ } \\
\mathrm{MPa}\end{array}$ & $\begin{array}{c}\text { Peak } \\
\text { stress/ } \\
\mathrm{MPa}\end{array}$ & $\begin{array}{c}\text { Peak } \\
\text { strain\% }\end{array}$ & $\begin{array}{c}\text { Maximum } \\
\text { permeability } \\
\text { coefficient } / 10^{-7} \mathrm{~cm} \cdot \mathrm{s}^{-1}\end{array}$ \\
\hline ST-2-1 & 2 & 15.2 & 6.2 & 621 \\
ST-2-2 & 2 & 14.0 & 5.6 & 567 \\
ST-2-3 & & 16.1 & 5.9 & 651 \\
ST-4-1 & & 18.6 & 4.8 & 214 \\
ST-4-2 & 4 & 19.3 & 5.2 & 236 \\
ST-4-3 & & 17.8 & 4.9 & 227 \\
ST-6-1 & & 31.2 & 5.1 & 152 \\
ST-6-2 & 6 & 32.6 & 5.5 & 147 \\
ST-6-3 & & 33.7 & 6.3 & 161 \\
ST-8-1 & & 39.8 & 6.3 & 97 \\
ST-8-2 & 8 & 41.3 & 5.8 & 94 \\
ST-8-3 & & 40.8 & 5.7 & 91 \\
\hline
\end{tabular}

Under different confining pressures, the permeability coefficient-axial strain curve has a similar change rule. With the increase of confining pressure, the permeability coefficient of briquette samples decreases gradually, and the higher the confining pressure, the more obvious the decrease of permeability coefficient is. This is mainly because the higher the confining pressure, the stronger the radial inhibition effect on briquette samples, and then, the crack opening inside the briquette will become smaller, that is, the width of the seepage throat will become narrower, which will lead to a smaller permeability value. The above laws indicate that the confining pressure has a significant effect on the permeability evolution of the briquette.

3.2. Analysis of Seepage Characteristics of Different Hoop Strains. In the process of permeability failure under axial compression, the circum-axial deformation reflects the evolution law of permeability in the process of yield, weakening, and failure from another Angle. The stress-circumferential strain curves and permeability coefficients of the samples under different constant confining pressures $(2,4,6$, and $8 \mathrm{MPa}$ ) are shown in Figure 4. 


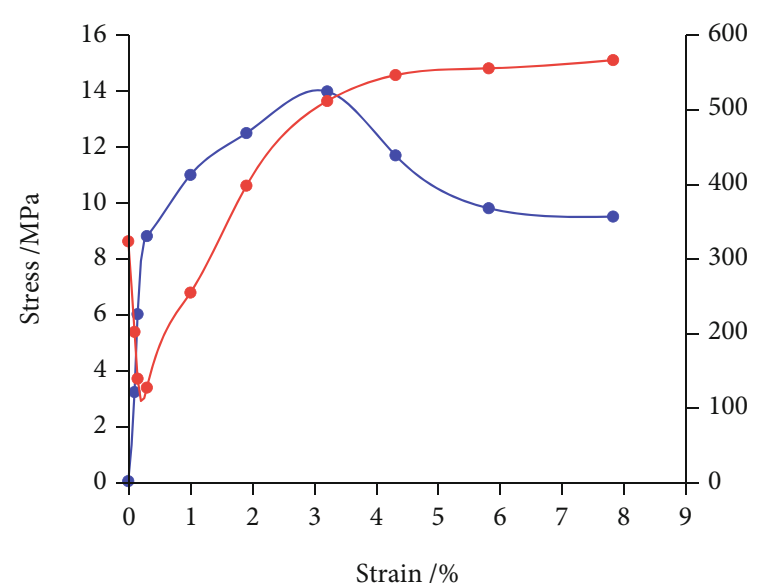

(a) Confining pressure $2 \mathrm{MPa}$

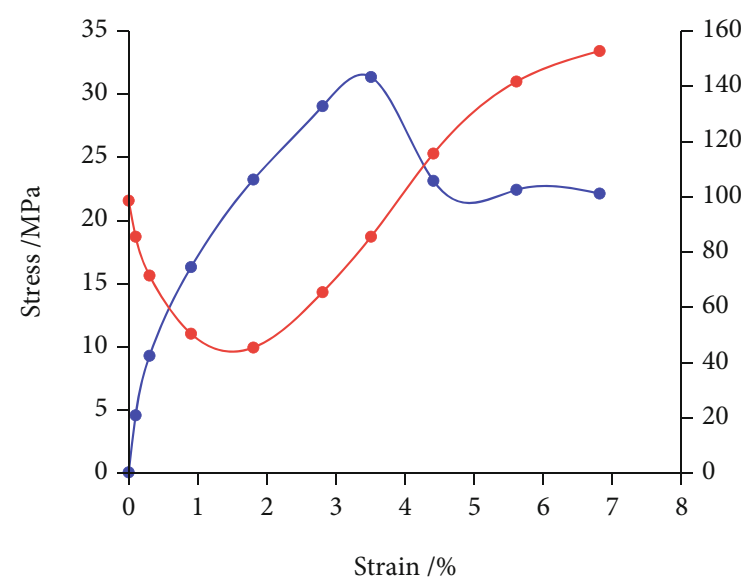

(c) Confining pressure $6 \mathrm{MPa}$

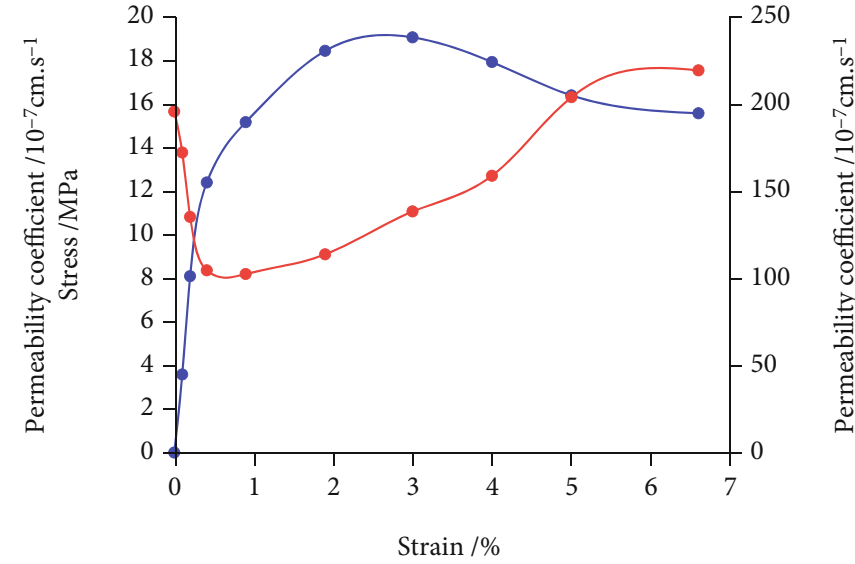

(b) Confining pressure $4 \mathrm{MPa}$
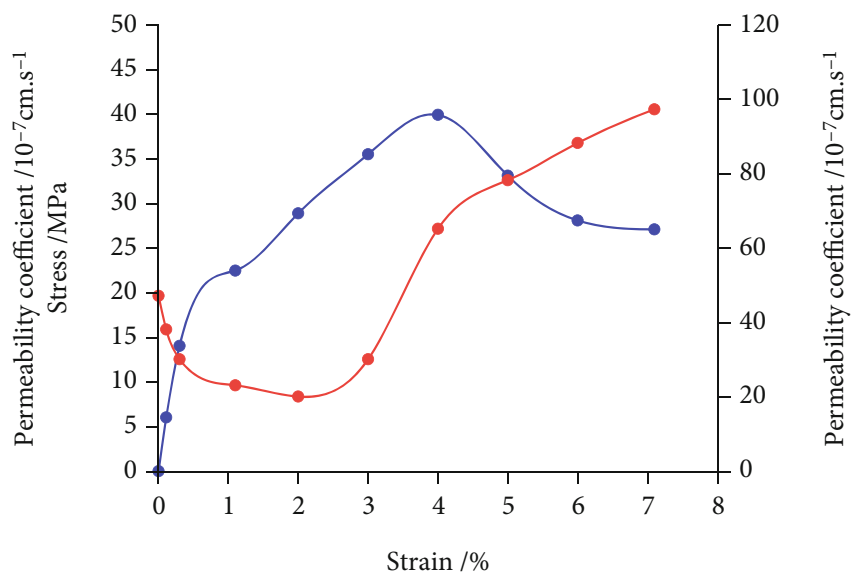

(d) Confining pressure $8 \mathrm{MPa}$

FIGURE 4: The relationship curve between hoop strain, permeability coefficient, and stress.

It can be seen from Figure 4 that the stresscircumferential strain curve and the stress-axial strain curve have the same trend of change, but the circumferential deformation more fully reflects the process of specimen yield, weakening, and failure than the axial deformation. In the process of specimen deformation and fracture, the change law of the influence of circum-axial strain and axial strain on permeability is the same, and the change law of permeability coefficient is basically the same. The permeability coefficient decreases with the increase of confining pressure, and the higher the confining pressure, the lower the permeability coefficient. The permeability coefficient corresponding to high confining pressure is far less than that corresponding to low confining pressure.

When the confining pressure is $2 \mathrm{MPa}$, the initial permeability coefficient is $323 \times 10^{-7} \mathrm{~cm} \cdot \mathrm{s}^{-1}$, and the maximum permeability coefficient after failure is $567 \times 10^{-7} \mathrm{~cm} \cdot \mathrm{s}^{-1}$. When the confining pressure is $4 \mathrm{MPa}$, the initial permeability coefficient is $191 \times 10^{-7} \mathrm{~cm} \cdot \mathrm{s}^{-1}$, and the maximum permeability coefficient after failure is $214 \times 10^{-7} \mathrm{~cm} \cdot \mathrm{s}^{-1}$. When the confining pressure is $6 \mathrm{MPa}$, the initial permeabil- ity coefficient is $98 \times 10^{-7} \mathrm{~cm} \cdot \mathrm{s}^{-1}$, and the maximum permeability coefficient after failure is $152 \times 10^{-7} \mathrm{~cm} \cdot \mathrm{s}^{-1}$. When the confining pressure is $8 \mathrm{MPa}$, the initial permeability coefficient is $47 \times 10^{-7} \mathrm{~cm} \cdot \mathrm{s}^{-1}$, and the maximum permeability coefficient after failure is $97 \times 10^{-7} \mathrm{~cm} \cdot \mathrm{s}^{-1}$. When briquette samples are subjected to initial stress, the initial value of permeability coefficient corresponding to the confining pressure of $2 \mathrm{MPa}$ is 6.87 times that corresponding to the confining pressure of $8 \mathrm{MPa}$. After the briquette sample is damaged, the maximum permeability coefficient corresponding to the confining pressure of $2 \mathrm{MPa}$ is 5.85 times that is corresponding to the confining pressure of $8 \mathrm{MPa}$.

The circumferential strain in the nonlinear compaction stage and the linear deformation stage is much smaller than the axial strain, and the circumferential strain deviates from the linear state more quickly than the axial strain, and the circumferential strain increases faster in the yield stage. Compared with the axial strain, the circumferential strain at the peak strength is smaller, and the increased range of the circumferential strain from the peak strength to the 
maximum permeability coefficient is obviously larger than that of the axial strain. The variation law of the circumferential strain is very similar to that of the permeability coefficient. In the nonlinear compaction stage and the linear deformation stage, the circumferential strain increases slowly, the variation range is small, and the permeability coefficient decreases. At the yield stage, the circumferential strain increases rapidly, and the permeability coefficient increases slightly and then sharply. Thus, compared with the axial strain, the permeability coefficient is more sensitive to the change of the circumferential strain.

\subsection{Analysis of Permeability Characteristics of Different} Confining Pressures. The test results of stress and permeability coefficient of samples in the process of deformation and failure under different confining pressures are shown in Table 3.

Under different confining pressures, the samples show different postpeak variation characteristics. The increase of confining pressure usually results in the axial stress corresponding to the peak stress of the samples changing greatly, and the slope of the post-peak curve gradually decreases. The change of confining pressure also has a strong effect on the dilatancy behavior of the sample. Under the condition of low confining pressure, the brittle failure of samples is accompanied by a large volume expansion. With the increase of confining pressure, the samples show obvious shear failure. The influence of confining pressure on the dilatancy of samples directly results in the difference in the permeability law of samples under different confining pressures. As can be seen from Table 3, (1) with the increase of confining pressure, the peak stress and residual strength increased significantly. (2) Both the initial and maximum values of the permeability coefficient of the sample decreased, and the maximum value of the permeability coefficient increased by $2.44 \times 10^{-4} \mathrm{~cm} / \mathrm{s}$ compared with the initial value at $2 \mathrm{MPa}$ confining pressure. When the confining pressure increases to $8 \mathrm{MPa}$, the maximum permeability coefficient only increases by $5.0 \times 10^{-6} \mathrm{~cm} / \mathrm{s}$ compared with the initial value. It can be seen that the increase of confining pressure makes the increase rate of maximum permeability greatly decrease. It can be seen that the permeability coefficient-strain curve gradually slows down with the increase of confining pressure.

In the process of specimen deformation and failure, the influence of confining pressure on the permeability of the specimen can be analyzed from two stages: first, the pore is the main seepage channel stage before the specimen failure; the second is that the main seepage channel stage is through fracture after specimen failure. The permeability coefficient of briquette samples in the initial stage decreases with the increase of confining pressure, showing a logarithmic function (see Figure 5(a)). The relationship between permeability coefficient and confining pressure in the initial stage is shown in Equation (2). After failure, the permeability coefficient of briquette samples gradually decreases with the increase of confining pressure, presenting a power function (see Figure 5(b)), and the greater the confining pressure, the more obvious the permeability coefficient decreases.
TABLE 3: Triaxial permeability test results under different confining pressures.

\begin{tabular}{|c|c|c|c|c|}
\hline \multirow{2}{*}{$\begin{array}{l}\text { Confining } \\
\text { pressure/MPa }\end{array}$} & \multicolumn{2}{|c|}{ Stress/MPa } & \multicolumn{2}{|c|}{$\begin{array}{c}\text { Permeability } \\
\text { coefficient } / 10^{-7} \mathrm{~cm} \cdot \mathrm{s}^{-1}\end{array}$} \\
\hline & $\begin{array}{l}\text { Peak } \\
\text { value }\end{array}$ & $\begin{array}{l}\text { Residual } \\
\text { value }\end{array}$ & $\begin{array}{l}\text { Initial } \\
\text { value }\end{array}$ & Maximum \\
\hline 2 & 14.0 & 9.5 & 323 & 567 \\
\hline 4 & 18.6 & 15.2 & 191 & 214 \\
\hline 6 & 31.2 & 22.1 & 98 & 152 \\
\hline 8 & 39.8 & 27.1 & 47 & 97 \\
\hline
\end{tabular}

The relationship between permeability coefficient and confining pressure is shown in Equation (3).

$$
\begin{gathered}
k=1304.7 \sigma_{3}^{-1.242} \quad R^{2}=0.9916, \\
k=-201.4 \ln \sigma_{3}+464.38 \quad R^{2}=0.9984 .
\end{gathered}
$$

3.4. Discussion. It is relatively easy to make briquette samples, which are pressed and formed by fine particles. The briquette samples have a standard size, smooth surface, and uniform texture. According to the mechanical characteristics of briquette samples, the total stress-strain curve of briquette samples changes gently, which is different from the existing mechanical characteristics of raw coal samples to some degree. The next step is to study the mechanical characteristics and seepage characteristics of raw coal samples under the coupling action of stress and seepage.

The type of coal samples under the action of stressseepage coupling of seepage characteristics shows that the permeability of specimen under low confining pressure conditions is greater than the high confining pressure permeability; based on the results, in the coal seam gas extraction in the process, take certain measures, such as hydraulic fracturing, and presplitting blasting, making smoke extracting seam permeability increases advantageous to the coal seam and efficient gas extraction.

\section{Penetration Mechanism in the Process of Coal Deformation and Failure}

Coal is a highly heterogeneous material with multiple cracks, and its deformation and failure process is essentially a dynamic evolution process of crack initiation, propagation, interaction, and finally, coalescence. The stress state of the coal body has a direct influence on the permeability, which can be theoretically proved by Lious's empirical formula

$$
k_{f}=k_{0} \mathrm{e}^{-\alpha \sigma}
$$

where $k_{f}$ is the permeability coefficient of the crack; $K_{0}$ is the initial permeability coefficient; $\alpha$ is constant; and $\sigma$ is the normal stress. The above formula reflects that the relationship between the permeability coefficient and the normal stress is negative exponential. With the increase of the normal stress, the permeability coefficient also increases. 


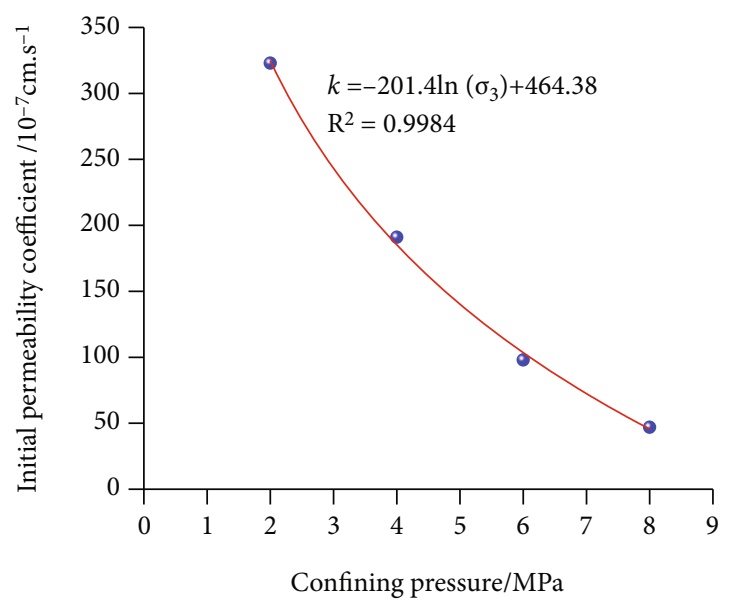

- Initial permeability coefficient

_ Fitting of initial permeability coefficient

(a) Initial permeability coefficient
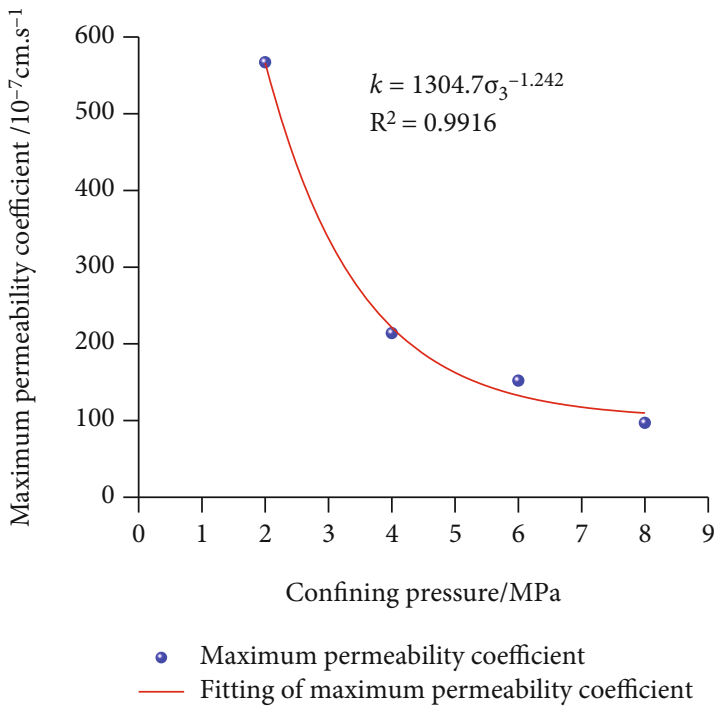

(b) Maximum permeability coefficient

FIgURE 5: The relationship between permeability coefficient and confining pressure.

The influence of the change of stress state on the permeability of briquette can be seen directly from the relationship curves of stress-axial strain, permeability, and stresscircumferential strain-permeability. When the stress-strain of briquette goes through five stages, nonlinear compaction stage, linear deformation stage, yield stage, strain-softening stage, and residual deformation stage, the permeability of briquette corresponding to each stage also changes correspondingly. The prepeak change of the briquette is mainly caused by compression deformation. At this time, the permeability of the briquette is relatively low, and the permeability is the lowest in the linear deformation stage, and the pores and cracks of the sample reach the maximum closure. With the gradual increase of strain, the crack inside the sample expands to reach through, and the briquette material loses its ultimate bearing capacity. In the postpeak stage of briquette, the strain continues to increase, the crack of the sample increases steadily, and the permeability coefficient also increases steadily. In addition, the circumferential strain can reflect the permeability of the sample more sensitively than the axial strain.

In fact, the permeability of coal type and the characteristics of coal itself also involve the concept of microscale seepage properties, such as topological structure characteristics of porous media itself medium and pore and fracture distribution, pore surface roughness, and the distribution of pores and fractures, and a porous media and the relationship between the fluid, such as surface wettability, adsorption and desorption characteristics, saturation distribution, and distribution details between phases.

Besides, in the process of seepage, the maximum permeability coefficient of briquette samples does not appear at the peak of stress-strain, but near its peak value. In short, the study of the seepage mechanism in briquette deformation and failure process has a very important guiding significance for mining engineering and oil and gas field development.

\section{Conclusions}

(1) The stress-strain of briquette goes through five stages: nonlinear compaction stage, linear deformation stage, yield stage, strain-softening stage, and residual deformation stage. The prepeak change of briquette is mainly caused by compression deformation, and the permeability of briquette is relatively low, and the permeability is the lowest in the linear deformation stage. After entering the yield failure stage, the permeability of the briquette begins to increase with the expansion and penetration of new fractures, and the maximum permeability of the briquette is basically near the peak value of briquette strength. In the residual deformation stage, the new crack increases slowly, and the briquette permeability coefficient changes steadily

(2) The stress-axial strain curve has the same variation trend as the stress-circumferential strain curve, but the circumferential deformation more fully reflects the process of specimen yield, weakening, and failure than the axial deformation. In the process of specimen deformation damage, hoop strain and axial strain effect on the permeability variation law of basic consistent, and the permeability coefficient with the increase of confining pressure and decreases, and the higher the confining pressure, the lower the permeability coefficient, the confining pressure increases rate under the same conditions; high confining pressure corresponding to the permeability coefficient of permeability coefficient is far less than the low confining pressure

(3) Confining pressure affects briquette permeability by affecting briquette expansion behavior. With the increase of the confining pressure, the permeability 
of the sample decreases, and the permeability coefficient decreases with the increase of the confining pressure at the initial stage, showing a logarithmic function. After failure, briquette samples show a power function change rule, and the greater the confining pressure is, the more obvious the permeability coefficient decreases

\section{Data Availability}

The data used to support the findings of this study are included within the article.

\section{Conflicts of Interest}

The authors declare that they have no conflicts of interest.

\section{Acknowledgments}

This paper was financially supported by the National Natural Science Foundation (51904010, 51874002, and 51874006) and Anhui Provincial Natural Science Foundation (1808085QE149, 2008085ME142, and 2008085ME147).

\section{References}

[1] H. Wang, W. Xu, and J. Zuo, "Compact rock material gas permeability properties," Physica B, vol. 449, no. 6, pp. 10-18, 2014.

[2] P. Xu and S. Q. Yang, "Permeability evolution of sandstone under short-term and long-term triaxial compression," International Journal of Rock Mechanics and Mining Sciences, vol. 85, no. 5, pp. 152-164, 2016.

[3] D. W. Hu, H. Zhou, F. Zhang, and J. F. Shao, "Evolution of poroelastic properties and permeability in damaged sandstone," International Journal of Rock Mechanics and Mining Sciences, vol. 47, no. 6, pp. 962-973, 2010.

[4] H. L. Wang, W. Y. Xu, C. J. Jia, M. Cai, and Q. X. Meng, "Experimental research on permeability evolution with microcrack development in sandstone under different fluid pressures," Journal of Geotechnical and Geoenvironmental Engineering, vol. 142, no. 6, article 04016014, 2016.

[5] T. Jiang, J. F. Shao, W. Y. Xu, and C. B. Zhou, "Experimental investigation and micromechanical analysis of damage and permeability variation in brittle rocks," International Journal of Rock Mechanics and Mining Sciences, vol. 47, no. 5, pp. 703-713, 2010.

[6] C. Zhu, M. C. He, M. Karakus, X. H. Zhang, and Z. G. Tao, "Numerical simulations of the failure process of anaclinal slope physical model and control mechanism of negative Poisson's ratio cable," Bulletin of Engineering Geology and the Environment, vol. 80, no. 4, pp. 3365-3380, 2021.

[7] B. Li, R. Bao, Y. Wang, R. Liu, and C. Zhao, "Permeability evolution of two-dimensional fracture networks during shear under constant normal stiffness boundary conditions," Rock Mechanics and Rock Engineering, vol. 54, no. 3, pp. 1-20, 2021.

[8] X. Zhang, H. Chen, C. Yao et al., "Seepage characteristics of triaxial compression-induced fractured rocks under varying confining pressures," International Journal of Geome Chanics, vol. 20, no. 9, article 04020160, 2020.
[9] B. Liu, J. Li, Q. Liu, and X. Liu, "Analysis of damage and permeability evolution for mudstone material under coupled stress-seepage," Materials, vol. 13, no. 17, p. 3755, 2020.

[10] J. Zhao, L. Bo, C. Juntao, and J. Ning, "Mechanism of seepagestress fault water inrush and grouting seal," Arablan Journal of Geosciences, vol. 13, no. 11, p. 404, 2020.

[11] S. Di, C. Jia, W. Qiao, W. Yu, and K. Li, "Theoretical and experimental investigation of characteristics of single fracture stress-seepage coupling considering microroughness," Mathematical Pronlems in Engineering, vol. 2017, article 6431690, pp. 1-12, 2017.

[12] Z. Cheng, H. Pan, Q. Zou et al., "Gas flow characteristics and optimization of gas drainage borehole layout in protective coal seam mining: a case study from the Shaqu coal mine, Shanxi Province, China," Natural Resources Research, vol. 30, no. 2, pp. 1481-1493, 2021.

[13] J. Annan, S. Zheng, and S. Wang, "Stress-seepage-damage coupling modelling method for tunnel in rich water region," Engineeging Computations, vol. 37, no. 8, pp. 2659-2683, 2020.

[14] W. Wang, Z. Luo, Y. Qin, J. Xiang, L. Wen, and S. Ma, "Multiphysics coupling model of rock mass considering damage and disturbance and its application," Advances in Civil Engineering, vol. 2018, 9 pages, 2018.

[15] S. Sha and Z. Guoxin, "Modeling of hydraulic fracture of concrete gravity dams by stress-seepage-damage coupling model," Mathematical Pronlems in Engineering, vol. 2017, pp. 1-15, 2017.

[16] Q. Liu, B. Lin, Y. Zhou, and Y. Li, "Permeability and inertial resistance coefficient correction model of broken rocks in coal mine goaf," Powder Technology, vol. 384, pp. 247-257, 2021.

[17] Q. Sun, J. Zhang, M. Li, and N. Zhou, "Experimental evaluation of physical, mechanical, and permeability parameters of key aquiclude strata in a typical mining area of China," Journal of Cleaner Production, vol. 267, article 122109, 2020.

[18] G. Dong, X. Liang, and Z. Wang, "The properties of a coal body and prediction of compound coal-rock dynamic disasters," Shock and Vibration, vol. 2020, Article ID 8830371, 13 pages, 2020.

[19] A. He, H. Fu, B. Huo, and C. Fan, "Permeability enhancement of coal seam by lower protective layer mining for gas outburst prevention," Shock and Vibration, vol. 2020, Article ID 8878873, 12 pages, 2020.

[20] D. Zhou, K. Li, H. Wang et al., "Permeability experiments with overburden pressure of coal measure reservoirs and numerical analysis of its stress sensitivity: a case study of Qinshui Basin, China," Energy Exploration \& Exploitation, vol. 38, no. 5, article 0144598720946495, pp. 1690-1705, 2020.

[21] C. Jiang, Z. Zhao, X. Zhang, J. Liu, D. Elsworth, and G. Cui, "Controlling effects of differential swelling index on evolution of coal permeability," Journal of Rock Mechanics and Geotechnical Engineering, vol. 12, no. 3, pp. 461-472, 2020.

[22] L. Zihao, R. Nino, and C. Cheng, "Using pressure pulse decay experiments and a novel multi-physics shale transport model to study the role of Klinkenberg effect and effective stress on the apparent permeability of shales," Journal of Petroleum Science and Engineering, vol. 189, p. 107010, 2020.

[23] Y. Wu, Z. Huang, K. Zhao, W. Zeng, Q. Gu, and R. Zhang, "Unsteady seepage solutions for hydraulic fracturing around vertical wellbores in hydrocarbon reservoirs," International Journal of Hydrogen Energy, vol. 45, no. 16, pp. 9496-9503, 2020 . 
[24] H. Fan, L. Wang, Y. Lu, Z. Li, W. Li, and K. Wang, "Height of water-conducting fractured zone in a coal seam overlain by thin bedrock and thick clay layer: a case study from the Sanyuan coal mine in North China," Environmental Earth Sciences, vol. 79, no. 6, p. 125, 2020.

[25] Z. Lu, S. Aimin, and W. Wang, "Permeability evaluation of clay-quartz mixtures based on low-field NMR and fractal analysis," Appliend Scienced-Basel, vol. 10, no. 5, p. 1585, 2020.

[26] H. W. Zhou and L. Zhang, "Effects of matrix-fracture interaction and creep deformation on permeability evolution of deep coal," International Journal of Rock Mechanics and Mining Sciences, vol. 127, p. 104236, 2020.

[27] J. Guo, J. Liu, Q. Li, and Z. Chen, "Study on the Permeability evolution and its formation mechanism of Xiaojihan aquifer coal seam under plastic flow," Geofluids, vol. 2020, Article ID 2147503, 16 pages, 2020.

[28] Q. Niu, L. Cao, S. Sang et al., "Study on the anisotropic permeability in different rank coals under influences of supercritical $\mathrm{CO}_{2}$ adsorption and effective stress and its enlightenment for $\mathrm{CO}_{2}$ enhance coalbed methane recovery," Fuel, vol. 262, p. $116515,2020$.

[29] H. Yuan, F. Agostini, F. Skoczylas, and J. Talandier, “About adsorption effects on the poroelastic properties and gas permeability of COx claystone," European Journal of Environmental and Civil Engineering, vol. 24, no. 2, pp. 267-282, 2020.

[30] K. Ma, L. Wang, Y. Peng, L. Long, S. Wang, and T. Chen, "Permeability characteristics of fractured rock mass: a case study of the Dongiiahe coal mine," Geomatics, Natural Hazards and Risk, vol. 11, no. 1, pp. 1724-1742, 2020.

[31] F. Long and L. Shimin, "Evaluation of permeability damage for stressed coal with cyclic loading: an experimental study," Intwrnational Journal of Coal Geology, vol. 216, article 103338, 2019.

[32] L. Zhang, X. C. Li, J.-X. Gao, Z.-X. An, X.-H. Yang, and B.S. Nie, "Creep characteristics and constitutive model of coal under triaxial stress and gas pressure," Energy Science \& Engineering, vol. 8, no. 2, pp. 501-514, 2020.

[33] A. Mathias Simon, "Storage coefficients and permeability functions for coal-bed methane production under uniaxial strain conditions," Transport in Porous Media, vol. 130, no. 2, pp. 627-636, 2019.

[34] Z. Yu, C. Wang, and B. Jing, "Permeability model of fractured rock with consideration of elastic-plastic deformation," Energy Science \& Engineering, vol. 8, no. 2, pp. 441-451, 2020.

[35] X. Zhang, C. Wu, Z. Wang, and D. Xu, "Postfracturing permeability prediction for CBM well with the analysis of fracturing pressure decline," Energy Science \& Engineering, vol. 7, no. 6, pp. 3111-3123, 2019.

[36] Y. Shuaifeng, M. Haifeng, C. Zhiheng et al., "Permeability enhancement mechanism of sand-carrying hydraulic fracturing in deep mining: a case study of uncovering coal in crosscut," Energy Science \& Engineering, vol. 7, no. 5, pp. 18671881, 2019.

[37] Y. Luo, "Influence of water on mechanical behavior of surrounding rock in hard-rock tunnels: an experimental simulation," Engineering Geology, vol. 277, article 105816, 2020.

[38] Y. Luo, F.-q. Gong, X.-b. Li, and S.-y. Wang, "Experimental simulation investigation of influence of depth on spalling characteristics in circular hard rock tunnel," Journal of Central South University, vol. 27, no. 3, pp. 891-910, 2020. 